\title{
O PARQUE URBANO DA CIDADE DE MAMBORÊ/PR, BRASIL: USOS E FUNÇÕES
}

\author{
Marcos Clair Bovo \\ Universidade Estadual do Paraná - Campus de Campo Mourão \\ mcbovo@yahoo.com \\ Ana Claudia Breitkreitz Fernandes Ayres \\ Universidade Estadual do Paraná- Campus de Campo Mourão \\ anacbfernades@gmail.com
}

\begin{abstract}
RESUMO
As áreas verdes urbanas são consideradas de grande relevância para a população, pois contribuem com as funções ecológica/ambiental, estético/paisagística e social, e também com a qualidade de vida da população urbana. Dentre as várias áreas verdes existentes inserem-se os parques urbanos, cuja principal função nas cidades é a sociabilidade entre os indivíduos, independente da classe social, pois todos usufruem dos mesmos benefícios. Diante disso, a pesquisa teve como propósito/intenção analisar as diferentes possibilidades de usos e funções gerados pelo Parque Ecológico Armando Alves de Souza na cidade de Mamborê-PR. A metodologia foi constituída de pesquisa bibliográfica em periódicos científicos, dissertações, teses, livros, pesquisa in loco, questionário aplicado aos frequentadores do parque e levantamento qualitativo da infraestrutura e dos equipamentos. Os resultados indicam que as funções ecológica, social, estética e social são proporcionadas pelo parque, porém, existem ainda carências de infraestruturas e de equipamentos.
\end{abstract}

Palavras-chave: Áreas verdes. Parques. Qualidade de vida.

\section{THE URBAN PARK OF THE CITY OF MAMBORÊ / PR, BRAZIL: USES AND FUNCTIONS}

\begin{abstract}
Urban green areas are considered of great relevance to the population, as they contribute to the ecological /environmental, aesthetic/landscape and social functions, as well as to the quality of life of the urban population. Among the several existing green areas are urban parks, whose main function in cities is sociability among individuals, regardless of social class, because all enjoy the same benefits. The purpose of this research was to analyze the different possibilities of uses and functions generated by the Armando Alves de Souza Ecological Park in the city of Mamborê-PR. The methodology consisted of bibliographical research in scientific journals, dissertations, theses, books, on-site research, questionnaire applied to park goers, and qualitative survey of infrastructure and equipment. The results indicate that the ecological, social, aesthetic and social functions are provided by the park, but there are still shortages of infrastructures and equipment.
\end{abstract}

Keywords: Green areas. Parks. quality of life.

\section{INTRODUÇÃO}

As áreas verdes urbanas são consideradas de extrema relevância para a qualidade de vida dos habitantes das cidades. Sendo assim, diante da realidade que se encontram a maioria das cidades brasileiras em relação à poluição, ausência de áreas para atividades físicas e de lazer e falta da integração entre as questões urbanas e ambientais, faz-se necessário à preservação, recuperação e ainda a criação de ambientes verdes nas cidades, pois são espaços destinados para momentos de lazer, sociabilidade, passeio, descanso e atividades físicas, no intuito de ter contato mais próximo com a natureza e melhorar a qualidade de vida da população.

\begin{tabular}{llllll}
\hline Caminhos de Geografia & Uberlândia - MG & v. 19, n. 67 & Set/2018 & p. 322-337 & Página 322
\end{tabular}


Diante disso, a pesquisa tem como objetivo analisar as diferentes possibilidades de usos e funções gerados pelo Parque Ecológico Armando Alves de Souza, na cidade de Mamborê.

Para alcançarmos os objetivos propostos, levantamos os seguintes questionamentos: Quais são as funções desempenhadas pelo parque no município de Mamborê? O parque é um atrativo para população? O parque possui infraestrutura suficiente para atender a população? Quais são os benefícios e as contribuições que o parque proporciona para a qualidade de vida da população? Existem pontos negativos? Quais?

Sendo assim, realizamos uma profícua discussão sobre esse tema, a qual, mediante informações levantadas de forma sistemática, contribuiu para o conhecimento da real importância desta área verde que foi escolhida justamente por ser um dos espaços públicos da cidade de Mamborê mais utilizado pela população. Esta pesquisa, além, de cooperar com a valorização e orientar o planejamento dos espaços verdes, buscou potenciar as suas funções essenciais e promover a utilização desses espaços, além de aumentar o grau de satisfação dos seus utilizadores.

\section{O parque urbano enquanto área verde: reflexões teóricas}

Os parques urbanos nem sempre foram vistos da forma como são na atualidade. O parque urbano do século XIX era a representação de certos ideais democráticos, onde se via neles a ideia de "oásis urbano". Para Ferreira (2005), dentre as causas da preocupação com a manutenção destes espaços, destacam-se a Revolução Industrial, a mecanização e o êxodo rural, associada às ideias de lazer e conceitos higienistas que se fortaleceram no emergir do século XX na Europa.

Naquele contexto, "os parques urbanos tinham como função primordial a recreação e o lazer, pois a estrutura urbana, que crescia rapidamente, clamava por espaços que atenuassem os problemas urbanos, funcionando como verdadeiros 'pulmões verdes' para o contexto da cidade" (BOVO; CONRADO, 2012, p. 53), ou seja, as pessoas precisavam de um ambiente que the proporcionassem bem-estar e harmonia, para poder se sentir livre do "caos" que estavam às cidades.

Com o passar do tempo, "os parques passaram a ser pensados não apenas como urbanismo ou equipamento de lazer e contemplação, mas como parte de um todo sistêmico que é a cidade" (WHATELY; et al 2008, p. 15), pois uma área verde não propicia somente um espaço de lazer, socialização e melhoria no aspecto da cidade, mas também como um todo. Sendo assim, o parque é uma "área superior a uma quadra típica urbana, em geral apresentando componentes da paisagem natural, vegetação, topografia, elemento aquático [...] edificações destinadas a atividades recreativas, culturais e/ou administrativas" (CARNEIRO; MESQUITA, 2000, p. 20).

Quanto ao o surgimento dos primeiros parques públicos no Brasil, ocorreu de forma diferente:

Não surgem da urgência social de atender às necessidades das massas urbanas das cidades do século XIX, visto que o Brasil, nesse período, não possuía uma rede urbana expressiva e as cidades brasileiras não tinham o porte das cidades europeias. No Brasil, os parques foram criados como figura complementar ao cenário das elites emergentes, que controlavam a Nação e procuravam construir uma configuração urbana semelhante aos modelos ingleses e franceses. A função a que se destinavam esses primeiros parques nas emergentes cidades urbanoindustriais europeias era o lazer e recreação (BOVO; CONRADO, 2012, p. 53-54).

Para Bovo (2009, p.53) "embora os parques tenham surgido no ambiente urbano, a sua compreensão exige considerar vários aspectos, seja porque representam uma continuidade, seja porque demonstram uma ruptura no modo de produzir o espaço urbano". Ainda para o autor, no decorrer do século passado "a criação de sistemas de parques urbanos foi ganhando cada vez mais importância, sendo que grande parte destas propostas previam que nas cidades do futuro os espaços livres públicos não seriam somente para o lazer da população, mas para a criação de cidades urbanizadas e saudáveis" (BOVO, 2009, p. 73).

Diante disso, os parques, na sociedade pós-moderna, surgem aliados ao modo de produção capitalista em virtude dos impactos tanto em níveis globais os parques urbanos surgem nas grandes, médias e pequenas cidades como necessidade de aproximação da população citadina ao meio natural, como forma de aliviar as tensões do dia a dia. O resultado dessas interações é a melhoria da qualidade de vida nas cidades. Outro ponto a considerar, o parque é um espaço público que possui inúmeras finalidades, sejam elas políticas, sociais, econômicos, culturais e ambientais, entre outras. 
Para Martins Júnior (1996, p. 7) "a área verde tem função de se constituir em um espaço 'social e coletivo', sendo importante para a manutenção da qualidade de vida. Por facilitar o acesso de todos, independentemente da classe social, promove integração entre a população de uma cidade".

Considerando que os parques possuem inúmeras finalidades, sejam elas políticas, sociais, econômicos, culturais, ambientais, psicológicas, ecológicas, dentre outros, Macedo e Sakata (2002), destacam que o parque é um espaço livre e público, destinado ao lazer de massa urbana e estruturado por vegetação. Já na concepção de Kliass (1993, p. 19) os parques são "espaços públicos com dimensões significativas e predominância de elementos naturais, principalmente cobertura vegetal, destinados à recreação". Lima (1994, p. 15) corrobora com a discussão quando destaca que o parque urbano "é uma área verde, com função ecológica, estética e de lazer, entretanto com uma extensão maior que as praças e jardins públicos".

Para Macedo e Sakata (2003, p. 14), o parque urbano é o "espaço de uso público destinado à recreação de massa [...] capaz de incorporar intenções de conservação cuja estrutura morfológica é autossuficiente, isto é, não é diretamente influenciada em sua configuração por nenhuma estrutura construída em seu entorno".

Podemos analisar diante das ideias apresentadas pelos autores que, os parques são vistos para muitos estudiosos e para uma significativa parcela da população como um lugar de recreação, de descanso, de lazer, contemplação e de contato com a natureza. Porém, para Marculino et al,(2010, p. 01) eles exercem muitas outras funções e benefícios, por:

\begin{abstract}
Propiciar sombra, purificar o ar, atrair aves, diminuir a poluição sonora, constituir fator estético e paisagístico, diminuir o impacto das chuvas, contribuírem para o balanço hídrico, valorizar a qualidade de vida local, assim como economicamente as propriedades ao entorno. Além disso, é fator educacional. Ademais, por se constituírem em muitos casos em refúgios de espécies de fauna e flora local, até com espécies ameaçadas de extinção, as árvores e áreas verdes urbanas tornam-se espaços territoriais importantíssimos em termos de preservação, aumentando ainda mais sua importância para o coletivo, além de agregar fatores ecológicos. (MARCULINO et al, 2010, p. 01).
\end{abstract}

Desta forma entendemos que as árvores propiciam uma interação entre o homem e a natureza; a vegetação contribui na estabilização climática, pois absorve parte da irradiação do sol, amenizando a temperatura e evitando a formação de ilhas de calor; exercem função recreativa, pois as pessoas procuram lugares frescos em dias de calor, e a vegetação existente em parques, proporcionam um local agradável para seus utilizadores.

Por outro lado, quando este é provido de infraestruturas e equipamentos, tais como: pista de caminhada, parquinho para as crianças, academia de Terceira Idade, quadras poliesportivas, contribui para atividades físicas, lazer etc. O parque também contribui com os aspectos de socialização entre os utilizadores, tendo em vista que: diminui a monotonia das atividades humanas, influenciando também na melhoria das relações sociais, ou seja, na convivência entre as pessoas, além de produzir um efeito psicológico nas pessoas, pelas cores das árvores e sua combinação com a luz. O som e o silêncio dos parques possibilitam um bem-estar nas pessoas que utilizam esses espaços públicos.

Segundo Bianchi (1992, p. 56), a arborização contribui também para amenizara poluição visual, pois as árvores são componentes "[...] urbanos e desempenham um papel importante, delimitando espaços, caracterizando paisagens, orientando visualmente e valorizando imóveis, além de integrar vários componentes do sistema". Sousa (2008) complementa a ideia de Bianchi (1992) quando destaca que as áreas verdes proporcionam o encontro de diferentes grupos sociais e podem proporcionar a harmonia do homem com a natureza, por meio de atividades de lazer ou mesmo descanso, influenciando a qualidade de vida das pessoas. Diante desse contexto os parques, enquanto áreas verdes assumiram e assumem grande importância na configuração do espaço urbano.

Na mesma direção, os autores Loboda e De Angelis (2005) argumentam que essas áreas verdes (parques, praças) onde predominam a vegetação são utilizadas com objetivos socioambientais, científicos e culturais, e devem primeiramente proporcionar o lazer a todos os cidadãos. Complementando as ideias dos autores Hildebrand (2001, p. 76), destaca que essas "áreas valorizam o ambiente e a estética, além de promoverem um excelente meio para as atividades da comunidade, criando importantes espaços e oportunidades de recreação e educação.

$\begin{array}{llllll}\text { Caminhos de Geografia } & \text { Uberlândia - MG } & \text { v. 19, n. } 67 & \text { Set/2018 } & \text { p. 322-337 } & \text { Página } 324\end{array}$


No que concerne às funções que os parques desempenham nas cidades, Vieira (2014, apud Bargos; MATIAS, 2011, p. 181, grifo nosso), também contribui dizendo que, os parques desempenham:

Função Social: possibilidade de lazer que essas áreas oferecem à população. Com relação a este aspecto, deve-se considerar a necessidade de hierarquização. Função Estética: diversificação da paisagem construída e embelezamento da cidade. Relacionada a este aspecto deve ser ressaltada a importância da vegetação. Função ecológica: provimento de melhorias no clima da cidade e na qualidade do ar, água e solo, resultando no bem-estar dos habitantes, devido à presença da vegetação, do solo não impermeabilizado e de uma fauna mais diversificada nessas áreas. Função Educativa: possibilidade oferecida por tais espaços como ambiente para o desenvolvimento de atividades educativas, extraclasse e de programas de educação ambiental.Função Psicológica: possibilidade de realização de exercícios, de lazer e de recreação que funcionam como atividades "antiestresse" e relaxamento, uma vez que as pessoas entram em contato com os elementos naturais dessas áreas.

Podemos analisar, portanto, que os parques públicos como áreas verdes urbanas possuem funções para a cidade, não somente como estética visando à integração entre os espaços construídos e os destinados à circulação, ecológica, cultural, ambiental, mas principalmente social, pois se refere também à oferta de espaços para lazer da população. É neste sentido, que os espaços livres de uso público merecem especial atenção sendo que possibilitam o acesso sem restrições a qualquer pessoa, devendo ser garantido o uso, a acessibilidade e a conservação por parte do poder público enquanto gestor e da população.

Diante disso, é necessário que tanto o poder público quanto a população compreenda a relevância desses espaços na sociedade e que os mesmos sejam incorporados nos planos urbanísticos, considerando que o planejamento em sua essência deve almejar a todos uma infraestrutura urbana de qualidade.

Assim sendo, os planejamentos devem considerar alguns pontos fundamentais, não apenas com relação à localização dos parques na malha urbana, mas também as espécies de árvores a serem introduzida, existência de área de esporte, de equipamentos (bancos, bebedouros, calçamento, iluminação, lixeiras, etc.) e também a segurança da população utilitária, dentre outros elementos sempre levando em consideração o tamanho da área e respeitando os princípios ambientais estabelecidos por lei.

De acordo com a reflexão sobre o uso dos parques feito por Jacobs (2003, p. 97), devemos "imaginar os parques urbanos como locais carentes que precisam da dádiva da vida e a aprovação conferida a eles. Isto está mais de acordo com a realidade, pois as pessoas dão utilidade aos parques e fazem dele, um sucesso, ou então e o condenam ao fracasso".

A relevância dos parques urbanos para as cidades são evidentes, mas apesar dos inúmeros benefícios elencados é possível perceber que muitas vezes a gestão desses espaços não é realizada de forma concisa, por falta recursos, pessoas preparadas, como também por falta de interesse do poder público.

\section{PROCEDIMENTOS METODOLÓGICOS}

A área de estudo compreende o Parque Ecológico Armando Alves de Souza, localizada na entrada principal da cidade de Mamborê (Figura 1) e próxima da área central, tendo como limites à rodovia de acesso à BR 369, a Avenida Abel Desidério de Araújo e a Avenida Augusto Mendes dos Santos,abrangendo uma área de $135.000 \mathrm{~m}^{2}$.

A metodologia utilizada neste artigo foi constituída de pesquisas bibliográficas sobre os temas, parques urbanos e áreas verdes, em livros, periódicos científicos, dissertações, teses, dentre outros que contribuíram para a fundamentação teórica e análise da pesquisa.

$\mathrm{Na}$ sequência realizamos a pesquisa in loco por meio de diferentes instrumentos, sendo: a) ficha de observação: cujos registros permitiram avaliar as estruturas e equipamentos e as condições do parque, levando-se em consideração a acessibilidade, as atividades desenvolvidas, a manutenção, segurança entre outros elementos (quadro 01). 
Figura 1: Localização do Parque Ecológico Armando Alves de Souza.

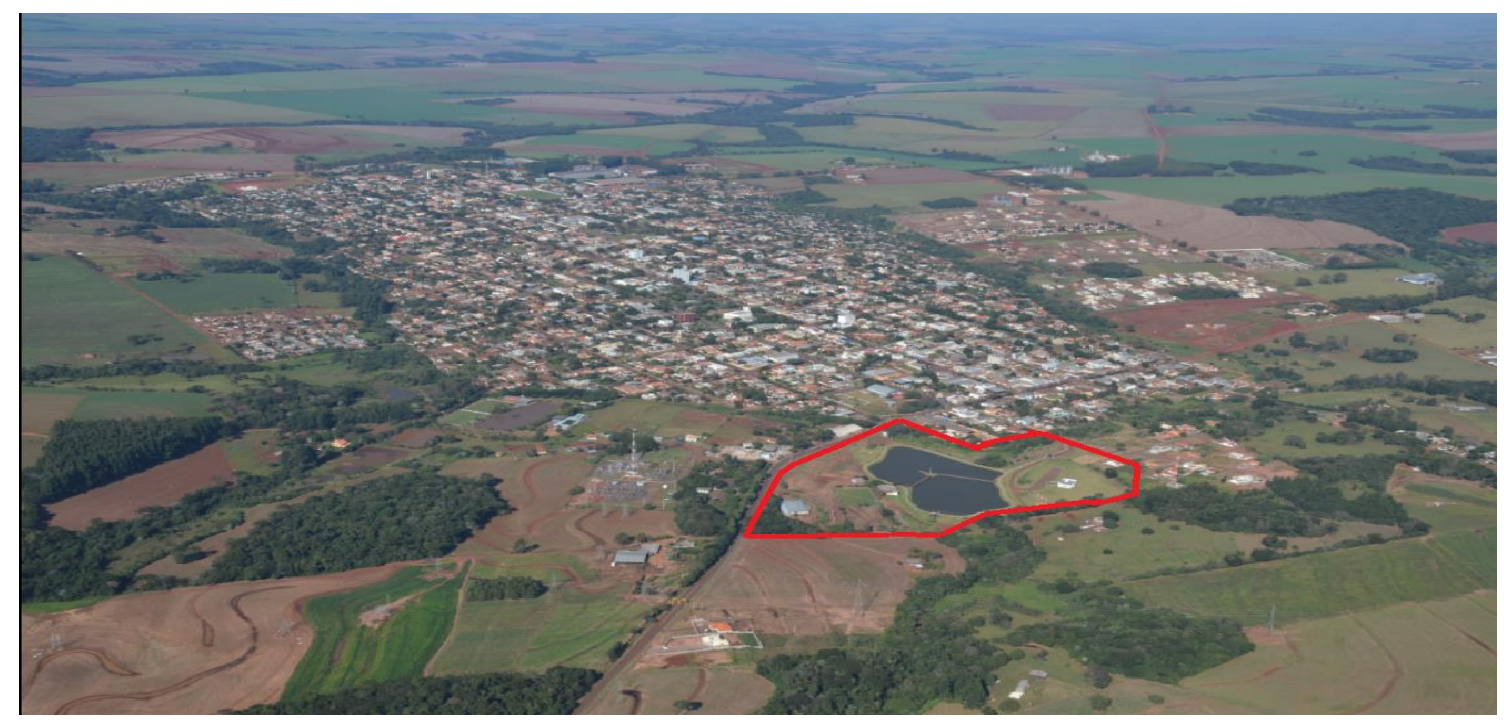

Fonte: Mamborê, 2016. Organizado pelos autores.

Quadro 01: Ficha de avaliação das estruturas e equipamentos e das condições do parque.

\begin{tabular}{|c|c|}
\hline Acessibilidade & Observações \\
\hline Acesso fácil ao parque & \\
\hline As estradas em volta são muito movimentadas Sim Não & \\
\hline Pode-se estacionar no local ou à volta deste Sim Não & \\
\hline Acesso facilitado a pé & \\
\hline Atividades que se podem realizar & Observações \\
\hline Apresenta passeio para percursos pedestres Sim & \\
\hline Espaço para a prática de desporto & \\
\hline Parque para crianças & \\
\hline Atividades organizadas para realização em grupo & \\
\hline Espaço destinados aos animais & \\
\hline Higiene e manutenção & Observações \\
\hline Manutenção e Limpeza dos espaços verdes & \\
\hline Presença de Lixeiras $\quad$ Sim_ Não & \\
\hline Segurança & Observações \\
\hline Estado de conservação destes percursos & \\
\hline Existem sinais de vandalismo nos percursos & \\
\hline Existe vandalismo & \\
\hline Existência de sinalizações de segurança & \\
\hline Existência de iluminação & \\
\hline Seguranças no parque & \\
\hline Existência de placa informativa & \\
\hline Lazer/redução do stress & Observações \\
\hline Espaço verde natural & \\
\hline Existência de bares & \\
\hline Existência de restaurantes & \\
\hline Existência de bancos & \\
\hline Existência de sombras & \\
\hline Existência de bebedouros & \\
\hline
\end{tabular}

Fonte: Organizados pelos autores. 
Quanto a avaliação da vegetação foram utilizados as informações permitiram analisar as condições das mesmas, levando-se em consideração os aspectos ambientais, tendo por base os seguintes elementos: a) a vegetação no contexto do parque (1- apresenta áreas de pavimentação danificadas pelas raízes; 2- apresenta poucas áreas pavimentadas danificadas pelas raízes; 3- não apresenta áreas danificadas pelas raízes); b) a vegetação e a iluminação do parque (1- as copas das árvores impedem a iluminação satisifatória do parque; 2- as copas das árvores impedem parcialmente a iluminação satisfatória do parque; c- as copas das árvores não impedem a iluminação satisfatória do parque); 3- identificação das vegetão do parque( 1- espécies arbóreas; 2- espécies arbóresa frutíferas; 3- espécies arbustivas; 4) espécies de forações.

Para classificar os aspectos físico-sanitários da vegetação utilizamos os seguintes parâmetros, adotados por Texeira (1991): bom: refere-se à vegetação que está isenta de sinais de praga, doenças ou injúrias mecânicas; satisfatório: a vegetações que apresentam pequenos problemas de pragas, doenças, danos físicos, necessitando de poda; ruim: quando se verificam severos danos provocados por pragas, doenças ou danos físicos; morta ou com morte aparente. Salientamos que esses parâmetros também foram utilizados nas pesquisas nos seguintes autores: Minak, Amorim, Martin (2006); Rezende, Santos (2010) entre outros.

Para diferenciar a qualidade paisagística, utilizamos os seguintes parâmetros: 1) bom: quando se apresentam sem danos, em condições de uso pleno; 2) satisfatório: quando se apresentam com pequenos danos, possibilitando o uso; 3) ruim: quando se apresentam com danos que impossibilitam o uso pleno. A qualidade paisagística refere-se "a análise do mobiliário", ou seja, dos equipamentos existentes nas áreas, assim como também dos aspectos gerais no que se refere à limpeza e conservação destas" Amorim (2001, p.41).

Realizamos, também, a aplicação de 25 questionários com 20 questões objetivas para a população de Mamborê, que utilizam o parque entre diferentes dias da semana e horários. Deste modo, buscamos conhecer a utilização, a importância para a população e as alterações que poderão tornar este espaço mais atrativo. Assim, no questionário, analisamos o perfil dos utilizadores; a caracterização da utilização, com recurso a questões relativas ao tempo gasto no deslocamento do local de residência ao parque; horário do dia preferido para a utilização do parque; que atividades realizam no parque, dentre outras.

Os questionários, segundo Gil (1999, p.128) pode ser definido "como a técnica de investigação composta por um número mais ou menos elevado de questões apresentadas por escrito às pessoas, tendo por objetivo o conhecimento de opiniões, crenças, sentimentos, interesses, expectativas, situações vivenciadas etc."

Sendo assim, a opção dos pesquisadores por 25 questionários se deve ao fato das respostas dos entrevistados serem semelhantes, não havendo dessa forma a necessidade de um número maior.

Ainda durante a pesquisa, obtivemos fotografias do local com a finalidade de registrar a realidade do parque.

\section{RESULTADOS E DISCUSSÕES}

O município de Mamborê está localizado na Mesorregião Centro-Ocidental Paranaense (Figura 2), limita-se com Campo Mourão e Farol ao Norte, com Boa Esperança e Juranda a Oeste, com Campina da Lagoa e Nova Cantu ao Sul e com Luiziana a Leste. Segundo dados do Censo demográfico 2010, 64,35\% da população de 13.968 habitantes estão concentrados na área urbana.

Quanto à área de pesquisa o Parque Ecológico Armando Alves de Souza está localizado no início do perímetro urbano do município, em um ponto estratégico, no qual todas as pessoas que chegam à cidade se deparam com o cartão postal, que é o parque.

É importante destacar que nessa área no passado, encontrava-se instalado o almoxarifado da prefeitura, sendo que o local era utilizado para a guarda das máquinas de grande porte, como carros pipa, caminhões e máquinas pesadas. A mesma passou por um processo de revitalização no qual foi planejado e implantado o parque que teve início em 2002, porém foi concluído somente no ano de 2007. 
Figura 2: Mesorregião Centro-Ocidental Paranaense com destaque para o município de Mamborê-PR e a Localização do Parque Armando Alves de Souza.

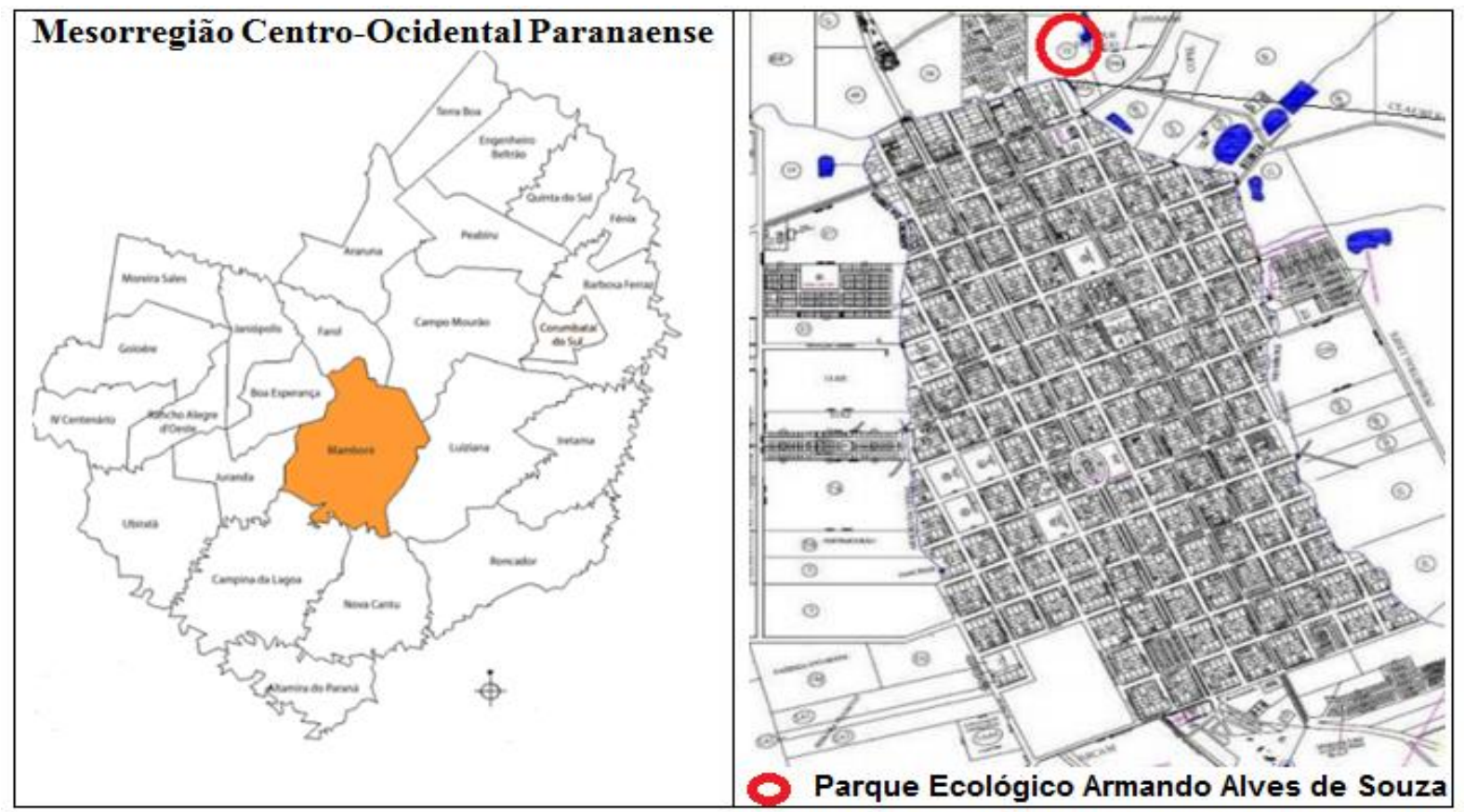

Fonte:CONCAM, 2012; MORIGI, Josimari de Brito, 2011.

Organizado pelos autores.

Na sequência,estruturamos a análise dos resultados da pesquisa em três momentos distintos, sendo: a) o Parque ecológico Armando Alves de Sousa enquanto área verde; b) análise das infraestruturas e dos equipamentos; c)análise do perfil dos utilizadores do parque.

\section{O Parque Ecológico Armando Alves de Souza enquanto área verde}

De acordo com o Art. 8으, § 1ํ, da Resolução CONAMA № 369/2006, considera-se área verde de domínio público o espaço público que desempenha função ecológica, paisagística e recreativa, propiciando a melhoria da qualidade estética, funcional e ambiental da cidade, sendo dotado de vegetação e espaços livres de impermeabilização.

Embora não haja formações florestais no interior da área do parque, sabe-se que faz parte da fitoregião da floresta estacional semidecidual. A floresta estacional semidecidual, cujo conceito ecológico está condicionado pela dupla estacionalidade climática. Uma tropical, com épocas de intensas chuvas de verão, seguidas por estiagem acentuada, e outra subtropical, sem período seco, mas com seca fisiológica provocada pelo intenso frio de inverno.

Nesse tipo de vegetação, a porcentagem de árvores caducifólias no conjunto florestal, e não das espécies que perdem as folhas individualmente, situa-se entre 20 e 50\% (IBGE, 1992).

A vegetação que compõem esta formação florestal é representada na região mais ao norte do Paraná pela sua forma mais exuberante, com dominância de espécies como: Parapiptadenia rigida, Luehea divaricata, Holocalix balansae, Gallesia integrifolia, Fícus spp, Cedrella fissilis, Colubrina glandulosa, Alchorniatriplinervia, Cabralea canjerana, (VELOSO et al., 1991). Baseado neste conhecimento a Prefeitura Municipal de Mamborê fez a reposição florestal ao entorno do Rio Mamborê, que passa nas imediações do parque com espécies dessa formação florestal.

Tendo por base a pesquisa in loco realizada no Parque Armando Alves de Souza constatamos que a vegetação está isenta de sinais de pragas ou doenças, não apresentando danos ocasionados pela ação humana, conforme metodologia desenvolvida por Teixeira (1991). Porém, grande maioria das árvores existentes foram plantadas no ano de 2012 e estão em fase de formação não propiciando sombra suficiente para os utilizadores do parque (Figura 3).

\begin{tabular}{llllll}
\hline Caminhos de Geografia & Uberlândia - MG & v. 19, n. 67 & Set/2018 & p. 322-337 & Página 328
\end{tabular}


Figura 3: Vista parcial da vegetação do parque.

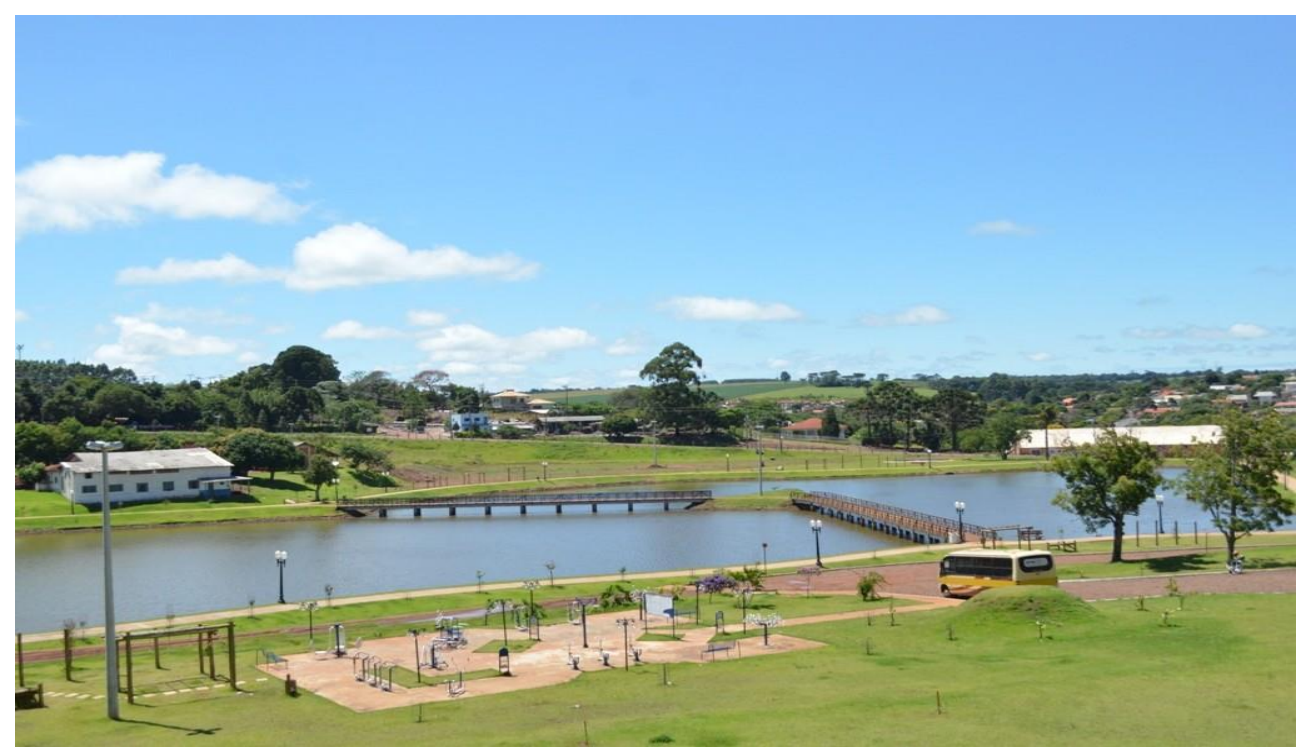

Foto: os autores.

A pouca vegetação existente em relação às copas das árvores, não impedem a iluminação do parque e a pavimentação não apresenta danos causado pelas raízes das árvores, haja vista que estas possuem porte pequeno, porém não descartamos as possibilidades de nos anos vindouros este dano possa ocorrer devido às árvores terem sido plantadas muito próximas à pista de caminhada.

No parque existe a presença de uma diversidade de espécies vegetais, tanto arbóreas, como arbóreas frutíferas, arbustivas, forrações e arbóreas frutíferas nativas, com presença de limão, chorão, grama esmeralda, noz pecan, cactos, ciriguela, hibisco, coqueiro, banana de macaco, jabuticaba, santa bárbara e sibipiruna.

Podemos observar que as árvores plantadas estão em ótima conservação e qualidade, algumas possuem cerca de proteção evitando que as mesmas sejam danificadas.

Vale salientar que o amplo gramado do parque favorece a impermeabilização da água da chuva, bem como, propicia um local saudável para os frequentadores do parque, que o utilizam para fazer piqueniques, jogar vôlei, tirar fotos, descansar, brincar com os filhos, dentre outras funções.

Dentre as sugestões visando à melhoria do parque indicamos: a) maior adensamento da vegetação no entorno da pista de caminhada e da área de lazer, servindo como uma "cortina" de proteção em relação ao monóxido de carbono e outros poluentes que vêm da rodovia; b) introdução de espécies que ajudem a manter o barranco mais estável, evitando desmoronamento; c) propor medidas em longo prazo visando sempre a melhoria dos aspectos físicos e sanitários da vegetação levando-se em consideração: a mão de obra treinada e especializada; acompanhamento do plantio e do crescimento; poda e tratamento obedecendo às técnicas adequadas; d) desenvolver políticas públicas visando a conscientização da população sobre a importância do parque enquanto áreas verde em desenvolvimento; e) plantio de maior número de espécimes, para que no futuro o parque possa propiciar áreas maiores de sombras, a fim de recompor a vegetação nativa da região.

Assim, de acordo com a pesquisa in loco, principalmente, no tocante às análises da importância da área pesquisada, ressaltamos que o parque proporciona bem-estar favorecendo a qualidade de vida dos habitantes da cidade.

\section{Análise das infraestruras e dos equipamentos do parque}

Neste item serão analisados as estruturas e equipamentos (mobiliário) do parque, visando uma melhor compreensão das análises dos dados obtidos utilizamos asseguintes informações obtidas de Lamas (1993, p. 44), quanto aos aspectos quantitativos, organizacional funcional; qualitativos e figurativos.

$\begin{array}{llllll}\text { Caminhos de Geografia } & \text { Uberlândia - MG } & \text { v. 19, n. } 67 & \text { Set/2018 } & \text { p. 322-337 } & \text { Página } 329\end{array}$


Aspectos quantitativos - Todos os aspectos da realidade urbana que podem ser quantificáveis e que se referem a uma organização quantitativa: densidade, superfícies, fluxos, coeficientes volumétricos, dimensões perfis, etc. Todos esses dados quantificáveis são utilizados para controlar os aspectos físicos da cidade.

Aspectos da organização funcional - Relacionam-se com as atividades humanas (habitar, instruir-se tratar-se, comerciar, trabalhar etc.) - e também com o uso de uma área, espaço edifício (residencial, escolar, comercial, sanitário, industrial, etc.), ou seja, o tipo de uso do solo. Uso a que é destinado e o uso de que ele faz.

Aspectos qualitativos - Referem-se ao tratamento dos espaços, ao "conforto" e à "comodidade" do utilizador... No meio urbano poderão ser caracterizados como o estado dos pavimentos [...] a acessibilidade [...] o conforto da iluminação etc.[...].

Aspectos figurativos - Os aspectos figurativos relacionam-se essencialmente com a comunicação estética. (LAMAS, 1993, p. 44).

Outro aspecto que devemos considerar se refere a função que o espaço público proporciona, ou seja, se os mobiliários são adequados aos utilizadores, sejam eles crianças, jovens e idosos. Neste sentido, utilizamos nesta pesquisa o conceito de mobiliário urbano de Ferrari (2004, p.240):

Mobiliário urbano (urban furniture, mobílie rurbain, mobilaje urbana). Conjunto de elementos materiais localizados em logradouros públicos ou locais visíveis desses logradouros e que complementam as funções urbanas de habitar, trabalhar, recrear e circular: cabinas telefônicas, anúncios, idealizações horizontal, vertical e aérea; postes, torres, hidrantes, abrigos e pontos de parada de ônibus, bebedouros, sanitários públicos, monumentos, chafarizes, fontes luminosas etc. (FERRARI, 2004, p.240).

A ideia de Ferrari (2004) nos leva a um nível mais compreensível daquilo que seria mobiliário urbano que será analisado a seguir.

A entrada do parque localiza-se em uma área de declividade na Avenida Augusto Mendes dos Santos, devido a isso durante a construção, foram feitos vários cortes com formações de platôs evitando o assoreamento do local. A entrada é pavimentada com pedras irregulares, com o objetivo de haver o máximo de absorção de água possível. O acesso ao mesmo é facilitado tanto a pé quanto por veículos.

$\mathrm{Na}$ parte externa do parque, destacamos a existência de luminárias tipo jardim, calçada para pedestres, pista de caminhada, gramado e placas indicando os recursos investidos na obra e lixeira.

O Parque possui dois estacionamentos: um externo (capacidade para aproximadamente 13 veículos) e outro interno (capacidade para aproximadamente 40 veículos). Ao lado do estacionamento interno, encontra-se uma academia de terceira idade (A.T.I.) composta por vários equipamentos. $\mathrm{Na}$ área ocupada pelos equipamentos da A.T.I. o solo é concretado e ao seu entorno possui pequenas árvores que foram plantadas com o objetivo de proporcionar sombra aos que utilizam deste espaço.

No local existem bancos de metal e lixeiras permeáveis também em metal. Devido às lixeiras serem permeáveis, não há acúmulo de água no interior das mesmas, impedindo a proliferação do mosquito Aëdes aegypti.

Os dados do Banco Mundial (2011) evidenciam que a população de terceira idade tem crescido em escala mundial, tendo em vista o aumento da expectativa de vida dos últimos anos. Diante disso, é importante que o poder público ofereça opções de lazer, criando espaços alternativos para o descanso, a contemplação a recreação e a prática de exercícios físicos, conforme afirma Bovo (2009).

Quanto aos aspectos quantitativos, organizacional/funcional, qualitativos e figurativos (estético) proposto por Lamas (1993) é possível de ser constatados na ATI conforme figura 05.

Ao lado da A.T.I, estão os banheiros para utilização dos frequentadores, pouco higienizados, sendo um masculino e outro feminino.

A pista de caminhada possui 730 metros de extensão e 2,70 de largura. No seu percurso possui lixeiras, academias para exercícios de musculação e abdominal (mais utilizada pelos jovens) construídas de madeira, bancos e toda área ás margens do lago é coberta por gramado rasteiro. Ao centro do lago existe uma pequena ilha portando uma grande luminária e tendo como acesso a ela duas pontes de madeira em ótimo estado de conservação, muito utilizada pelos frequentadores para alimentarem os peixes que existem no lago (Figura 6).

$\begin{array}{llllll}\text { Caminhos de Geografia } & \text { Uberlândia - MG } & \text { v. 19, n. } 67 & \text { Set/2018 } & \text { p. 322-337 } & \text { Página } 330\end{array}$


Figura 5: Academia de Terceira Idade do Parque.

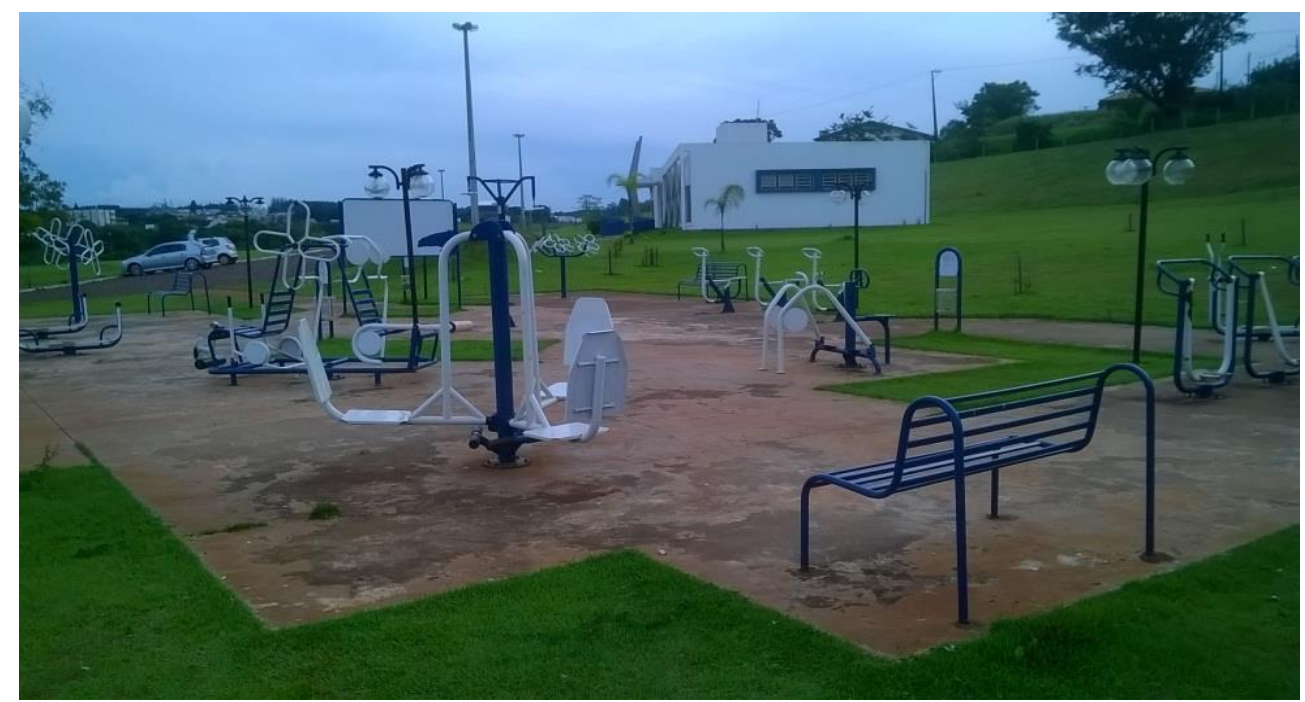

Foto: os autores.

Existem placas no interior do parque informando aos utilizadores que é proibido entrar na água e nadar, jogar lixo no lago e entrada de animais.

No que diz respeito à presença de bebedouros para os utilizadores, existe apenas uma torneira d'água próxima à ponte, sendo este o único local onde os utilizadores podem tomar água, enquanto estão praticando exercícios físicos, caminhando e correndo, bem como quando fazem o uso das academias instaladas. Sendo assim, os mesmos devem se precaver quanto à questão de água para beber, pois o parque não é provido de bebedouros.

Próximo à nascente do lago foi construído caixas concretadas que tem por finalidade captar a água aumentando seu volume e reduzindo a quantidade de resíduos sólidos que possam vir principalmente em períodos chuvosos, garantindo a qualidade da água do lago e reduzindo o efeito de assoreamento tão comum neste tipo de ambiente construído.

Devido o parque possuir segurança 24 horas, por guarda municipal, o mesmo não apresenta sinais de vandalismo.

Figura 6: Pontes de madeira no parque.

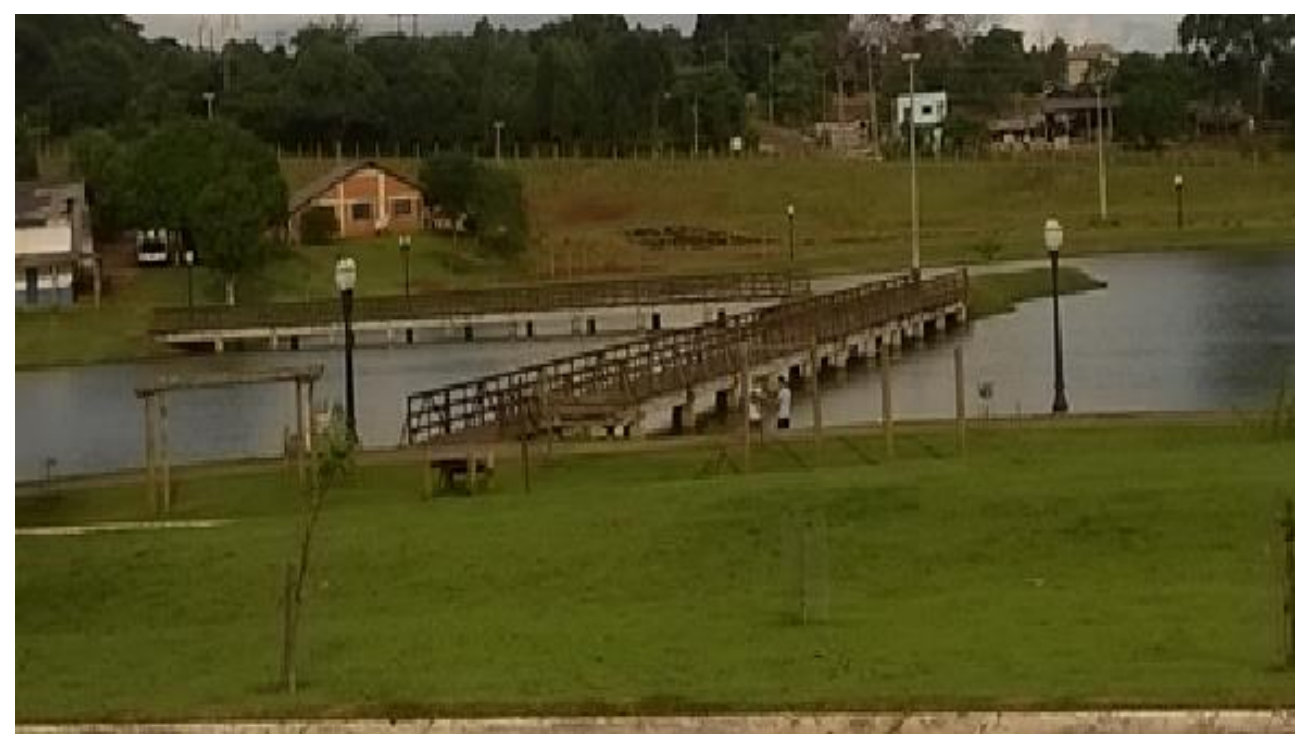

Foto: os autores. 
Algo que chama a atenção no parque é o Centro de Eventos (Figura 7) que existe ao lado do estacionamento interno, este se encontra concluído há quase um ano, mas nunca foi utilizado pelos cidadãos, pois o poder público não realizou a inauguração e não liberou para a população o seu uso, estando no momento fechado.

Quando estava em fase de construção, por diversas vezes a obra sofreu com rachaduras, isto porque a obra foi construída em área que antes era alagada, e como o solo não é estável, houve movimentos significativos que moveu a estrutura da obra, provocando prejuízos para o município e para a empresa que executou os serviços, pois tiveram que arcar com as despesas de reparo.

Vale salientar que a obra iniciou no dia 15 de outubro do ano de 2012, com 304,06 metros, com verbas oriundas do Ministério do Turismo, no valor de $\mathrm{R} \$ 300.948,16$ (trezentos mil, novecentos e quarenta e oito reais e dezesseis centavos), cuja prestação de contas foi aprovada em dezembro de 2015. Quando questionado na Prefeitura Municipal o não uso do mesmo, foi dito que existe uma indecisão do poder público em saber o que implantar no local para ser utilizado pelas pessoas.

O parque também conta com um chafariz, em formato de meio círculo, e quando está em funcionamento é um atrativo para as pessoas que frequentam o parque, principalmente as crianças.

O entorno do parque é residencial e comercial, com destaque maior ao loteamento que foi construído nas imediações do parque, o que tem aumentado os valores dos lotes e contribuído com a especulação imobiliária.

No ano de 2015, o município foi contemplado com recursos provenientes do Governo Federal para a construção de um Complexo Esportivo no Parque, composto por quadra de piso sintético (grama) com $1.269,00 \mathrm{~m}^{2}, 01$ quadra piso de areia com $1.269,00 \mathrm{~m}^{2}, 01$ quadra piso concreto com $1.269,00 \mathrm{~m}^{2}$ e 01 Conjunto de Sanitários com $38,70 \mathrm{~m}^{2}$, no valor de $\mathrm{R} \$ 600.000,00$ (seiscentos mil reais), solidificando assim, a necessidade da ampliação de espaço para o cidadão mamboreense, criando um espaço de lazer e assim melhorar a qualidade de vida de seus usuários. A obra ainda não teve início, pois ainda não foi licitada.

Figura 7: Centro de eventos do parque.

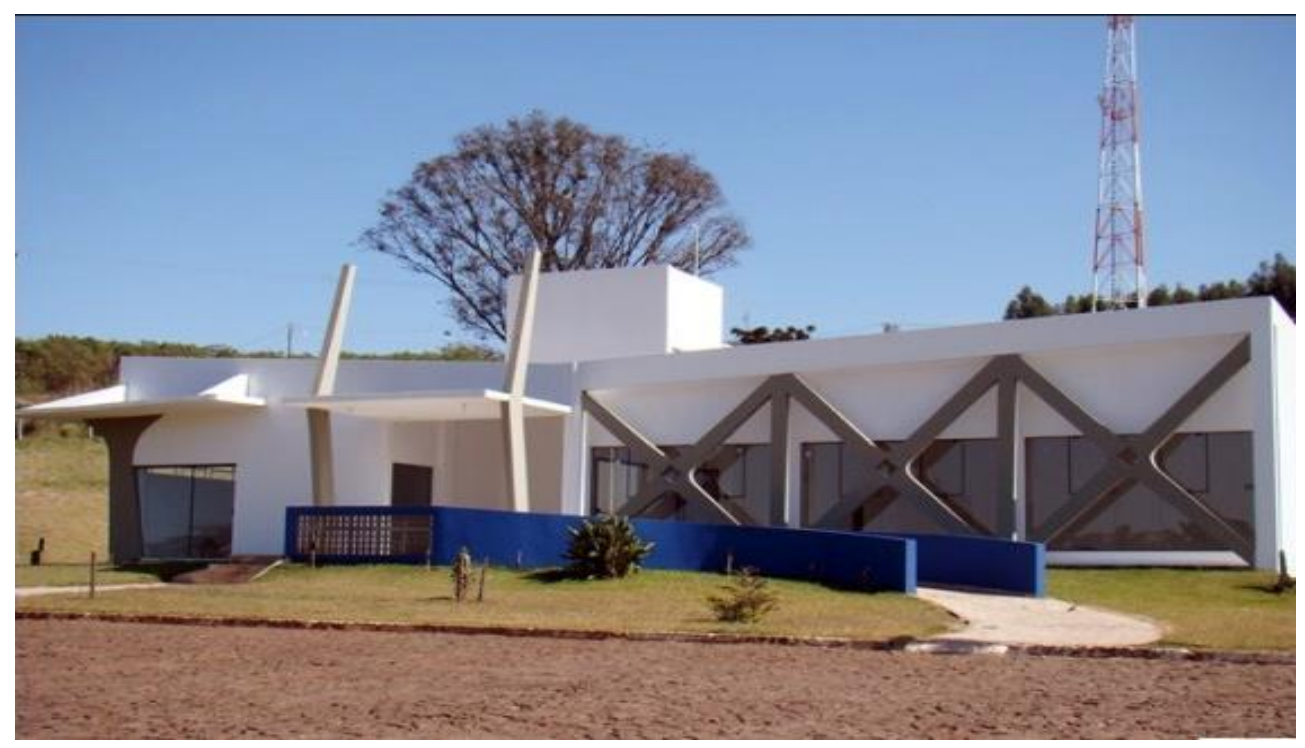

Foto: os autores.

O parque não possui bares e restaurantes. A iluminação do mesmo é satisfatória no período noturno, contendo luminárias baixas tipo jardim no interior do parque, não impedindo a frequência dos utilizadores do parque no período noturno.

O parque colabora ainda na proteção da fauna, principalmente a avifauna que encontrou nesta área abrigo e alimentos necessários à sua sobrevivência, como garças, patos e inúmeros pássaros pequenos, que também tornam um atrativo natural para os utilizadores.

$\begin{array}{llllll}\text { Caminhos de Geografia } & \text { Uberlândia - MG } & \text { v. 19, n. } 67 & \text { Set/2018 } & \text { p. 322-337 } & \text { Página } 332\end{array}$


A Prefeitura Municipal desenvolve soltura de peixes no lago, e para tal atividade é convidada os alunos das escolas municipais para acompanhar a atividade, resgatando os valores da Educação Ambiental.

Durante as visitas a campo, foi observada a utilização de alguns materiais improvisados pelos frequentadores, como caixas de papelão utilizadas como escorregador para as crianças, pois o parque não possui nenhum tipo de A.P.I - Academia de Primeira Idade.Este tipo de ação é possível, pois o parque possui alguns locais com bastante declive, o que possibilita as crianças a utilizarem o barranco para tal brincadeira. Este é um dos pontos negativos observados no parque, pois devido a esse tipo de brincadeira está prejudicando o gramado.

A implantação de uma Academia da Primeira Idade seria de suma importância no parque, pois esta aliada no cuidado e bem-estar das crianças. Promove e estimula o exercício físico de forma divertida, melhorando a saúde da população desde cedo, combatendo o sedentarismo e a obesidade infantil, ampliando as capacidades motoras, mentais e sociais das crianças.

Devido à infraestrutura do parque, como o gramado e o lago, vários casais de noivos com a família, utilizam este local para cerimônias de casamento e tirar fotografias.

De forma geral, o Parque Ecológico Armando Alves de Souza encontra-se em bom estado de conservação no que se refere a seus mobiliários e estruturas, porém sugerimos ao poder público, a instalação de bebedouro, parque infantil, telefone público, bicicletário, mesas de jogos, playground/API e lanchonete.

\section{Análise do perfil dos utilizadores do parque}

Com o objetivo de qualificar e definir as diferentes possibilidades e funções desempenhadas pelo parque e conhecer a característica do público realizamos a aplicação de 25 questionários, tendo como público alvo as pessoas que utilizam o espaço.

Dessa forma neste item buscamos analisar: breve caracterização dos utilizadores, a importância atribuída ao parque, a frequência de visitas, a distância de deslocamento, a relação do usuário com o parque, destacando a sua importância para a melhora da qualidade de vida, avaliação da qualidade dos serviços de segurança do parque, dentre outros.

Os dados da pesquisa mostraram a presença de um público heterogêneo, composto por estudantes, professores, técnico de informática, gerente de projetos, gerente administrativo, engenheiro civil, aposentado, do lar, pedreiro, desempregado, fotógrafo, segurança patrimonial, baba, assessor de promotoria e manicure, entre outros.

Quanto aos frequentadores do parque tanto a presença masculina quanto feminina foi significativamente proporcional, sendo que dos 25 questionários, 13 foram do sexo masculino e 12 do sexo feminino, demonstrando que os utilizadores do parque não se restringem somente a um único grupo.

A faixa etária predominante foi a de 19 a 40 anos, seguida de 12 a 18 anos, 41 a 60 anos, criança e acima de 60 anos.

A maioria dos frequentadores possuem ensino superior, correspondendo a $28 \%, 20 \%$ ensino fundamental incompleto, $16 \%$ ensino médio, $16 \%$ ensino superior incompleto, $16 \%$ ensino fundamental, $4 \%$ analfabeto. Destes, $32 \%$ utilizam o parque nos finais de semana.

Quando perguntado aos utilizadores se possuem tempo para o lazer, a maioria dissera possuir tempo, correspondendo a $64 \%$ dos utilizadores e $36 \%$ disseram não possuir tempo para o lazer, $72 \%$ destacaram que não utilizam outro espaço público da cidade com a mesma finalidade do parque, porém, $28 \%$ que disseram fazer uso de outro espaço existente na cidade com a mesma finalidade.

Devido à frequência ser maior aos finais de semana, o período da tarde é o escolhido pelos utilizadores, seguido do período da manhã e por fim o período da noite. Vale ressaltar que o horário de funcionamento do parque se inicia as $06 \mathrm{~h} 00 \mathrm{~min}$ com término as $22 \mathrm{~h} 00 \mathrm{~min}$.

Em relação às atrações que o parque oferece, destacou-se o descanso como a tração principal, seguida do verde, caminhadas, a sombra, ATI, o lago, a pesca e o passeio com os filhos, demonstrando dessa forma a importância que esta área verde possui para a população

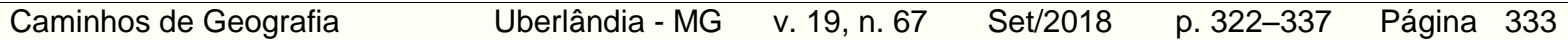


mamboreense, haja vista que é uma cidade pequena, sem atrativos para seus moradores, para tanto, o parque consegue atrair as pessoas para frequentá-lo.

Com relação às percepções que os utilizadores possuem em relação ao parque, a maioria dissera a tranquilidade, seguida do silêncio, conforto, satisfação, paz, ar puro, alegria e harmonia em frequentar o parque.

Para Vieira (2004), as áreas verdes tendem a assumir diferentes papeis na sociedade e suas funções devem estar inter-relacionadas no ambiente urbano, de acordo com o tipo de uso a que se destinam, sendo assim a função do lazer foi a mais significativa entre os frequentadores, como também a função ecológica e estética para a cidade.

Neste sentido, os resultados vão ao encontro de Milano (1990), colocando que a principal função do sistema de áreas verdes urbanas não deve ser apenas a criação de refúgios para que as pessoas possam "escapar" da cidade. Além disso, essas áreas devem possibilitar à população momentos de lazer e recreação em convívio com a natureza, respeitando sua vivência urbana e contato com outras pessoas.

Sabemos que as áreas verdes resultam em muitos benefícios para as pessoas, para tanto, quando questionamos os frequentadores sobre o parque, no tocante aos benefícios lazer, seguido de saúde física e mental, contato com a natureza e conforto.

É importante colocar que $100 \%$ dos que responderam aos questionários disseram que o parque não exclui classes sociais e que o mesmo ajuda a cidade ser mais justa nas questões ambiental principalmente, como também social e econômica.

Quando as pessoas vão ao parque, harmonizam com ele, sendo assim, dos 25 questionários aplicados, um pouco mais da metade dos utilizadores conseguem entrar em harmonia com a natureza do parque admirando o verde, outros lendo, descansando, caminhando e pescando, deixando evidente que presença do "verde" no parque contribui para uma sensação de tranquilidade e liberdade, o que não consegue sentir enquanto está na rotina do dia a dia na cidade.

Constatamos também que, $40 \%$ dos seus usuários permanecem nele uma hora, $8 \%$ menos de uma hora, $20 \%$ duas horas, $4 \%$ três horas e $28 \%$ mais de 3 horas. Diante destes resultados, observamos que o parque não é um local somente de passagem, mas sim de convivência, pois as pessoas que o frequentam não permanecem por menos de uma hora.

Notamos que, a maioria dos frequentadores se deslocam mais de dez quadras para ter acesso ao parque, mostrando que a distância não é um empecilho para as pessoas virem até o parque realizar suas atividades, ou somente para apreciar a paisagem e sentir o frescor de seu verde.

Quando questionado sobre a avaliação da segurança do parque, $28 \%$ disseram que a segurança é razoável, $60 \%$ disseram que está bom e $12 \%$ concluíram que a segurança do parque está excelente, até porque o parque possui segurança patrimonial 24 horas.

Muitos dos entrevistados após responderem ao questionário comentaram sobre o parque, alguns chegaram a definir o parque como um "pedacinho do céu", um local de paz, de fazer amizades, de alegria, "retiro espiritual", dentre outras.

Diante dos resultados, ressaltamos Dourado e Silva (2005), pois quando revemos a história da humanidade vemos que havia uma relação íntima entre homem e natureza, contudo o avanço tecnológico modificou essa relação e muito se perdeu do ponto de vista da qualidade ambiental. É nesse contexto que se resgata a importância dos parques, no cotidiano das pessoas que vivem nas cidades, sendo que a maioria o considera uma espécie de "refúgio", onde se busca tranquilidade e condições melhores de bem-estar. Famílias inteiras pescam nas tardes liberadas pelo município (evento mais importante realizado pela Prefeitura na visão dos utilizadores).

Diante disso, o parque é relevante para a população, uma vez que a utilização desse ambiente tem papel importante, pois exerce uma espécie de fuga para a liberdade (MUNNÉ, 1980) aos seus utilizadores em pleno ambiente urbano.

Sendo assim, diante dos resultados aqui expostos, é necessário que o poder público municipal mantenha o cuidado do parque, não deixando que o abandono e o descaso tomem posse do local. Por outro lado, para termos resultados ainda melhores, é necessário que o poder público invista seus recursos para melhorar este ambiente tão importante para os moradores da cidade de Mamborê.

$\begin{array}{llllll}\text { Caminhos de Geografia } & \text { Uberlândia - MG } & \text { v. 19, n. } 67 & \text { Set/2018 } & \text { p. 322-337 } & \text { Página } 334\end{array}$




\section{CONSIDERAÇÕES FINAIS}

As considerações finais aqui apresentadas são respostas das análises dos questionamentos e de observações do Parque que direcionaram a elaboração desta pesquisa.

Quanto aos aspectos sanitários da vegetação do parque, apresentam boas condições, estando isentas de sinais de praga, doenças ou grandes estragos. Quanto à qualidade paisagística do parque, concluímos que este não apresenta danos que afetam as condições de uso recebendo a classificação "boa", no entanto, notamos a falta de árvores de portes médio e grande, devido às mesmas serem plantadas pouco tempo, estando em fase de formação, por outro lado, a existência do gramado cuidado adequadamente e seus extratos arbustivos não impedem a frequência das pessoas no parque.

Os resultados mostram um alto percentual de respostas positivas que o fator gerador de maior efeito positivo em todos os sentidos é a presença do verde e do lago, associadas à sensação de bem-estar, contato com a natureza, favorecendo a saúde física e mental, destacando que a função ecológica juntamente com a social estética e de lazer é cumprida pelo parque.

Durante as visitas de campo realizadas no parque e com embasamento nos questionários, pudemos constatar que muitas pessoas utilizam o parque para descansar, ler, brincar, caminhar, pescar namorar e se divertir fazem do gramado existente, um espaço extremamente significativo para suas práticas de lazer.

Constatamos a plena convicção que com a implantação do parque do lago, o município de Mamborê teve um atrativo a mais para oferecer aos visitantes e principalmente a população local contribuindo também com a valorização dos lotes no seu entorno e melhoria da qualidade de vida da população local.

Outro aspecto importante a ser ressaltado é que a região da implantação do parque do lago se tratava de um local com alto grau de degradação ambiental. Sendo assim, com a intervenção do poder público em implantar uma área de lazer no local, além de recuperar a área proporcionou uma boa visão paisagística, considerada o cartão postal da cidade.

Baseado no princípio de preservação ambiental e buscando aumentar a qualidade de vida da população do município, concluímos que o parque possui um grande papel social. Trata-se de um local onde as famílias passam horas agradáveis do seu tempo desenvolvendo atividades variadas e que as afastam do estresse do dia a dia. Permite um aumento na socialização da comunidade, pois é um local destinado a atividades em conjunto e ainda colabora para a divulgação da cultura.

Apesar da grande importância que o parque proporciona para os seus utilizadores, foi possível averiguar a partir da análise e evidenciação dos mobiliários urbanos presentes, que no mesmo, ainda há falta de alguns equipamentos que são primordiais em um ambiente como esse, tais como: bicicletário, mesas de jogos, playground, A.P.I, lanchonete, bebedouro de água e maior quantidade de árvores para proporcionar sombra em proporções maiores.

Estas são apenas algumas sugestões que se delineiam nessas considerações finais, porém inúmeras outras podem ser aplicadas no Parque urbano de Mamborê, algumas das quais apareceram ao longo da construção deste artigo. Neste sentido, ressalta-se o quanto é importante às análises, discussões e reflexões sobre essa temática no Planejamento Urbano das cidades.

\section{REFERÊNCIAS}

AMORIM, Margarete C. da C. T. Caracterização das áreas verdes em Presidente Prudente/SP. In: SPOSITO, Maria Encarnação Beltrão (org). Textos e contextos para a leitura geográfica de uma cidade média. Presidente Prudente: 2001.

BANCO MUNDIAL. Envelhecendo em um Brasil mais velho: implicações do envelhecimento populacional para o crescimento econômico, a redução da pobreza, as finanças públicas e a prestação de serviços. Brasília, 2011. Disponível em: http://siteresources.worldbank.org/BRAZILINPOREXTN/Resources/38171661302102548192/Envelhecendo_Brasil_Sumario_Executivo.pdf. Acesso em: 13 jun. 2016.

BARGOS, Danúbia Caporusso; MATIAS, Lindon Fonseca. Áreas verdes urbanas: um estudo de revisão e proposta conceitual. Revista da Sociedade Brasileira de Arborização Urbana, v. 6, n. 3,

$\begin{array}{llllll}\text { Caminhos de Geografia } & \text { Uberlândia - MG } & \text { v. 19, n. } 67 & \text { Set/2018 } & \text { p. 322-337 } & \text { Página } 335\end{array}$


p. 172-188, 2011. Disponível em:<http://www.revsbau.esalq.usp.br/artigos_cientificos/artigo169publicacao.pdf>. Acesso em: 04 out. 2016.

BOVO, Marcos Clair. Áreas verdes urbanas, imagem e uso: um estudo geográfico sobre a cidade de Maringá-PR. Tese (Doutorado em Geografia). Programa de Pós-Graduação em Geografia, Universidade Estadual Paulista. Presidente Prudente, 2009.

BOVO, Marcos Clair; CONRADO, Denner. O parque urbano no contexto da organização do espaço da cidade de Campo Mourão (PR), Brasil. Caderno Prudentino de Geografia, v. 1, n. 34, p. 50-71, 2012. Disponível em:<http://revista.fct.unesp.br/index.php/cpg/article/view/1845> Acesso em 04 set. 2016.

BOVO, Marcos Clair; AMORIM, Margarete Cristiane de Costa Trindade. Análise e diagnóstico dos parques urbanos em Maringá (PR), Brasil. Geo UERJ, v. 2, n. 22, p. 323-349, 2011. Disponível em:http://www.e-publicacoes.uerj.br/index.php/geouerj/article/view/2466>. Acesso em 15 de junho 2016.

BIANCHI, C. G.; GRAZIANO, T. T. Caracterização e análise das áreas verdes urbanas de Jaboticabal-SP. In: Anais. Congresso Brasileiro Sobre Arborização Urbana. Vitória, 1992.

CARNEIRO, Ana Rita Sá; MESQUITA, Liana de Barros. Espaços livres do Recife. Prefeitura da Cidade do Recife. Universidade Federal de Pernambuco 2000.

CONAMA. Conselho Nacional de Meio Ambiente. Resolução n. 369, de 28 de março de 2006. Disponível em: <http://www.mma.gov.br/port/conama/legiabre.cfm?codlegi=489>. Acesso em 12 de julho de 2016.

FERRARI, Celson. Dicionário de Urbanismo. São Paulo: Disal, 2004.

FERREIRA, ADJALME DIAS. Efeitos positivos gerados pelos parques urbanos. Dissertação (Ciências Ambientais). Programa de Pós-Graduação em Ciências Ambientais. Universidade Federal Fluminense. Rio de Janeiro, 2005.

FUNDAÇÃO INSTITUTO BRASILEIRO DE GEOGRAFIA E ESTATÍSTICA - IBGE. BRASIL. Rio de Janeiro: IBGE, 1992.

GIL, Antônio Carlos. Métodos e técnicas de pesquisa social. São Paulo: Atlas, 1999.

HILDEBRANDT, E. Avaliação econômica dos benefícios gerados pelos parques urbanos:

Estudo de caso em Curitiba - PR. 2001. 137 f. Tese (Doutorado em Engenharia Florestal)- Setor de Ciências Agrárias, Universidade Federal do Paraná, Curitiba, PR.

CONCAM. Diagnóstico dos municípios da CONCAM. Maringá, 2012. Disponível em <http://www.observatoriodasmetropoles.net/download/relatorio_comcam.pdf>. Acesso em $11 \mathrm{de}$ outubro de 2016.

JACOBS, Jane. Morte e vida de grandes cidades. São Paulo. Martins Fontes, 2001.

JUNIOR, Osmar Pires Martins. Uma cidade ecologicamente correta. Goiânia. AB Editora, 1996.

KLIASS, Rosa Grená. Os Parques Urbanos de São Paulo. São Paulo. Pini, 1993.

LIMA, J. H.M; BOVO. M. C. Parque do lago de Mamborê/PR: uma análise investigativa da proposta de implantação e execução das obras sobre a ótica dos mamboreenses. In: Anais do VI Encontro de Produção Científica e Tecnológica Campo Mourão. Campo Mourão, 2011.

LOBODA C. R.; DE ANGELIS, B. L. D. Áreas verdes públicas urbanas: Conceitos, usos e funções. Ambiência - Revista do Centro de Ciências Agrárias e Ambientais, Guarapuava, v. 1, n. 1, jan/jun. 2005. Disponível em:

<http://revistas.unicentro.br/index.php/ambiencia/article/view/157>. Acesso 15 jun. 2016.

LAMAS, José Manuel Ressano Garcia. Morfologia Urbana e Desenho da Cidade. Lisboa:

Fundação Calouse Gulbenkian/ junta Nacional de Investigação Científica e Tecnológica, 1993.

MACEDO, Silvio Soares. SAKATA Francine Gramacho. Parques Urbanos no Brasil. Brazilian Urban Parks.São Paulo: In: Coleção Quapá. EDUSP, 2003

$\begin{array}{llllll}\text { Caminhos de Geografia } & \text { Uberlândia - MG } & \text { v. 19, n. } 67 & \text { Set/2018 } & \text { p. 322-337 } & \text { Página } 336\end{array}$


MILANO, Miguel Serediuk. Planejamento da Arborização Urbana: relações entre áreas verdes e ruas arborizadas. In: Anais. Encontro Nacional Sobre Arborização Urbana. Curitiba: FUPEF. 1990.

MINAK Mônica: AMORIM Margarete C. C. T.; MARTIN Encarnita. Ensaio teórico-metodológico sobre as áreas verdes aplicado a um estudo de caso: diagnóstico dos referenciais terminológicos e a realidade in loco. Revista Formação, Presidente Prudente, v. 1, n. 13, jan/jun. 2006. Disponível em: <http://revista.fct.unesp.br/index.php/formacao/article/view/834>. Acesso 15 jun. 2017.

MORIGI, Josimari de Brito; HAHN, Fábio André. A colonização do município de Mamborê e a formação do espaço urbano (1930-1940). Revista Geomae, Campo Mourão, v. 2, n. 1, p. 263-267, 2oㅡㄴ Sem/2011.

MUNNÉ, Frederic. Psicología del tiempo libre. México: um enfoque crítico. Trillas, 1980.

MAMBORÊ, Prefeitura Municipal. Departamento de Planejamento. Mamborê, 2016.

SILVA, I. M.; RAMOS, M. P; BRITO J. S.; Análise das funções das praças do bairro centro de Teresina-PI. II Congresso de Pesquisa e Inovação da Rede Norte Nordeste de Educação Tecnológica João Pessoa -PB - 2007.

SOUZA, Felipe Silveira. O Espaço público contemporâneo: a complexidade vista a partir de parques urbanos de Porto Alegre. Dissertação (Mestrado em Geografia). Programa de PósGraduação em Geografia. Universidade Federal do Rio Grande do Sul. Porto Alegre, 2008.

REZENDE Tiago M; SANTOS Douglas G. Avaliação quali-quantitativa da arborização das Praças Do Bairro Jaraguá, Uberlândia - MG. REVSBAU, Piracicaba - SP, v.5, n.2, 2010. Disponível em:< http://www.revsbau.esalq.usp.br/artigos_cientificos/artigo108-publicacao.pdf>. Acesso dez. 2017.

TEIXEIRA, I. F. SANTOS, N. R. Caracterização das áreas verdes do perímetro urbano de Santa Catarina- RS. In: Anais Encontro Nacional de Estudos sobre o Meio Ambiente. Londrina, 1991.

VELOSO, Henrique. Pimenta. et. al. A.Classificação da vegetação brasileira adaptada a um sistema universal. Rio de Janeiro: IBGE, Departamento de Recursos Naturais e Estudos Ambientais, 1991.

VIEIRA, P. B. H. Uma visão geográfica das áreas verdes de Florianópolis, SC: estudo de caso do Parque Ecológico do Córrego Grande (PECG). Universidade Federal de Santa Catarina. Trabalho de Conclusão de Curso, Florianópolis, SC, 2004.

Recebido em: 19/04/2017

Aceito para publicação em: 28/04/2018 